\title{
Pseudomeningocele after Laminectomy: Case report and literature review
}

Address for correspondence: Antonio Marcos da Silva Catharino. Rua Gavião Peixoto 70, Room 811. Icaraí - Niterói

- Rio de Janeiro - Brazil. CEP: 24230-100.

Email: neurocurso@globo.com

How to cite this article: Nunes NSM, Nascimento JSF, Hasegawa JCF, Andrade MCAP, Toneti KAS, Vaz IMB, et al. Pseudomeningocele after Laminectomy: Case report and review. G Med Sci. 2020; 1(6): 049-052.

https://www.doi.org/10.46766/thegms.neuro.20122406

Nicolle dos Santos Moraes Nunes', Jacqueline Stephanie Fernandes do Nascimento ${ }^{2}$, Juliana Cristina Ferreira Hasegawa ${ }^{3}$, Milena da Costa Araújo Pereira Andrade ${ }^{4}$, Karine Anauha da Silva Toneti $^{5}$, Isabele de Mello Bentes Vaz ${ }^{6}$, Lucas Cruz Ferreira ${ }^{7}$, Marco Orsini ${ }^{8}$, Gilberto Canedo Martins $\mathrm{Jr}^{9}$, Antônio Marcos da Silva Catharino $0^{10^{*}}$

'Undergraduate student of Medicine at the Iguaçu University (UNIG). Nova Iguaçu, RJ, Brazil. https://orcid.org/0000-0003-0336-2261

${ }^{2}$ Undergraduate student of Medicine at the Iguaçu University (UNIG). Nova Iguaçu, RJ, Brazil. https://orcid.org/0000-0003-1847-3829

${ }^{3}$ Undergraduate student of Medicine at the Iguaçu University (UNIG). Nova Iguaçu, RJ, Brazil. https://orcid.org/0000-0003-3129-7006

${ }^{4}$ Undergraduate student of Medicine at the Iguaçu University (UNIG). Nova Iguaçu, RJ, Brazil.

${ }^{5}$ Undergraduate student of Medicine at the Iguaçu University (UNIG). Nova Iguaçu, RJ, Brazil. https://orcid.org/0000-0002-8303-8623

${ }^{6}$ Undergraduate student of Medicine at the Iguaçu University (UNIG). Nova Iguaçu, RJ, Brazil.

7Undergraduate in Medicine at the Iguaçu University (UNIG). Nova Iguaçu, RJ,

Brazil. https://orcid.org/0000-0002-6960-9645

${ }^{8}$ Neurologist. Professor of Neurology at the Iguaçu University (UNIG). Nova Iguaçu, RJ, Brazil. Caduceu Institute - Postgraduate Medical Continuing School - SP. https://orcid.org/0000-0001-6680-3795

${ }^{9}$ Neurologist, Professor of Medicine at Universidade Iguaçu, Universidade Iguaçu UNIG / RJ, Nova Iguaçu, Brazil. https://orcid.org/0000-0002-8181-7930

${ }^{10}$ Neurologist. Professor of Neurology at the Iguaçu University (UNIG). Nova Iguaçu, RJ, Brazil. https://orcid.org/0000-0002-5736-1486
Copyright: () 2020 Nicolle dos Santos Moraes Nunes, Jacqueline Stephanie Fernandes do Nascimento, Juliana Cristina Ferreira Hasegawa, Milena da Costa Araújo Pereira Andrade, Karine Anauha da Silva Toneti, Isabele de Mello Bentes Vaz, Lucas Cruz Ferreira, Marco Orsini, Gilberto Canedo Martins Jr, Antônio Marcos da Silva Catharino. This is an Open Access article distributed under the Creative Commons Attribution License, which permits unrestricted use, distribution, and reproduction in any medium, provided the original work is properly cited.

\begin{abstract}
Pseudomeningoceles are rare complications of laminectomy surgery. Such clinical condition results from an inadvertent surgical dural rupture. We describe in the present study the report of a patient who developed iatrogenic pseudomeningocele in the lumbar region after performing a left laminectomy in L5 topography. After the neurological assessment of the patient, bilateral hypoaesthesia was observed, in addition to a floating bulging in the lumbar region that was accentuated during the valsalva maneuver, with the hypothesis of a pseudomeningocele.
\end{abstract}

Keywords: iatrogenic pseudomeningocele; spurious meningocele; laminectomy; dural rupture; surgery. 


\section{Introduction}

Pseudomeningocele, also called extradural cyst, extradural pseudocyst, spurious meningocele, iatrogenic meningocele, postoperative diverticulum, or even arachnoid cyst, is an uncommon complication after laminectomy surgery [1]. The terms allude to a spherical space filled with liquid that is located dorsally to the thecal canal at the site of the surgical incision [2]. The liquid contained in this space is of similar density to the cerebrospinal fluid (CSF), and may or may not have communication with the subarachnoid space [2].

During extradural surgery, as is the case with laminectomy, the dura mater can be ruptured by direct trauma, excessive traction of both the dura mater and the nerve root, or dural laceration of sharp bone fragments [3]. Pseudomeningoceles are caused by CSF leakage into soft tissues, eventually forming a fibrous capsule. When the dura mater is ruptured, but the arachnoid remains intact, it may herniate and protrude through the dura mater forming an arachnoid-coated bag [3]. CSF pulsations can push the pseudomeningocele into the soft tissue and affect its size, shape and location [3].

Post-laminectomy arachnoid cysts are frequently present in the lumbar region, and have variable clinical presentations, including asymptomatic patients. The manifestations most associated with this injury include: a floating mass that is exacerbated by the valsalva maneuver, headache, nausea, vomiting, or radicular pain (in cases where there is nerve root compression through the cyst) $[4,5]$.

Although it is a rare complication, pseudomeningocele can lead to unfavorable outcomes for the patient, including the need for new surgery to repair the dural rupture and perform pseudomeningocele excision, in addition to late infections [4]. Thus, the objective of the present study is to report, with the aid of images, the case of a patient who developed a pseudomeningocele after laminectomy surgery due to herniated disc located in the lumbar spine.

\section{Case report}

E.L.O., 42 years old, male, complained of hypoesthesia in the left lower limb. He reported laminectomy 2 years ago for treatment of lumbar disc herniation. On physical examination, a depressible bulging, that was exacerbated by the valsalva maneuver, was observed in the lumbar region, at surgical incision topography (Figure 1). Preoperative magnetic resonance imaging shows diffuse bulging of the lumbar disc in L4-L5 and L5-S1 with an extruded component in the last segment (Figure 2), and control magnetic resonance imaging, 2 years after surgery, revealed L5 laminectomy, disc protrusion paramedian on the left in L5-S1, liquid collection isointense to the
CSF, without contrast impregnation, located in the laminectomy bed and next to the dural sac, extending to the subcutaneous fat through a thin path that accompanies the L5 spinous process, suggestive pseudomeningocele (Figure 3).

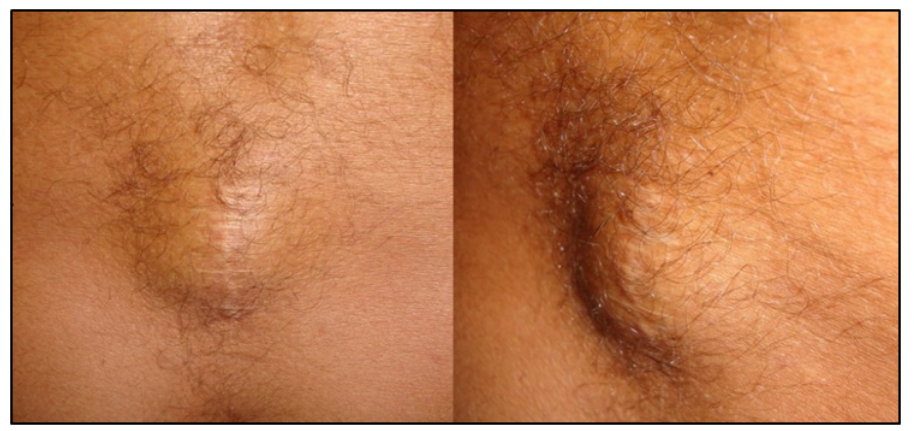

Figure 1: Lumbar depressiblebulging, that was exacerbated by the valsalva maneuver

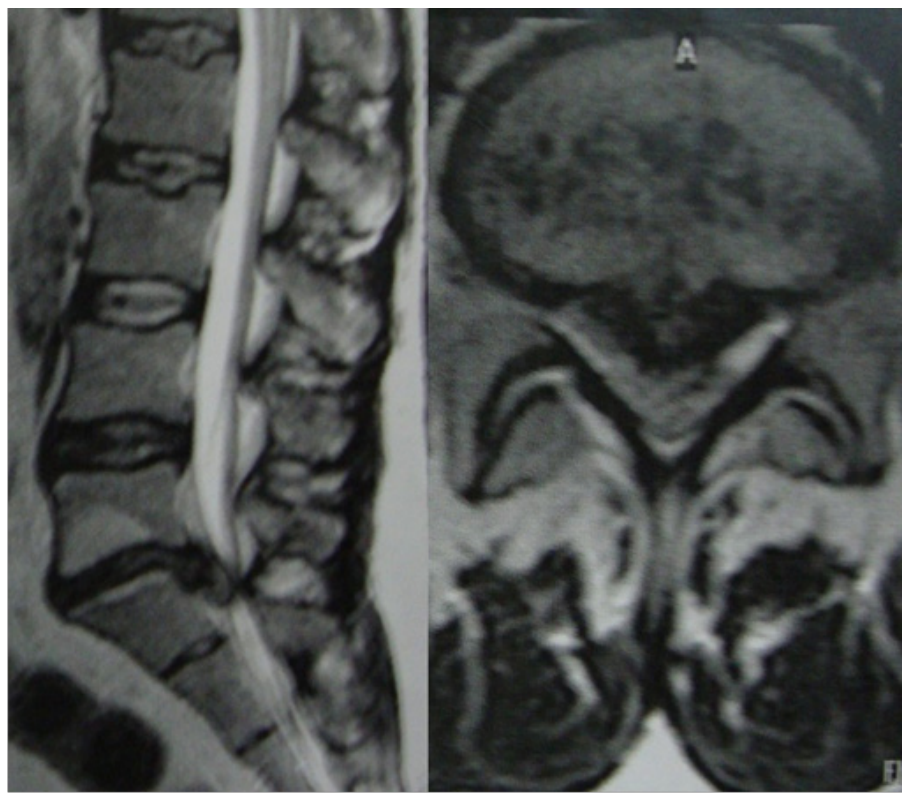

Figure 2: Preoperative magnetic resonance imaging shows diffuse bulging of the lumbar disc in $\mathrm{L} 4-\mathrm{L} 5$ and $\mathrm{L} 5-\mathrm{S} 1$ with an extruded componente. 


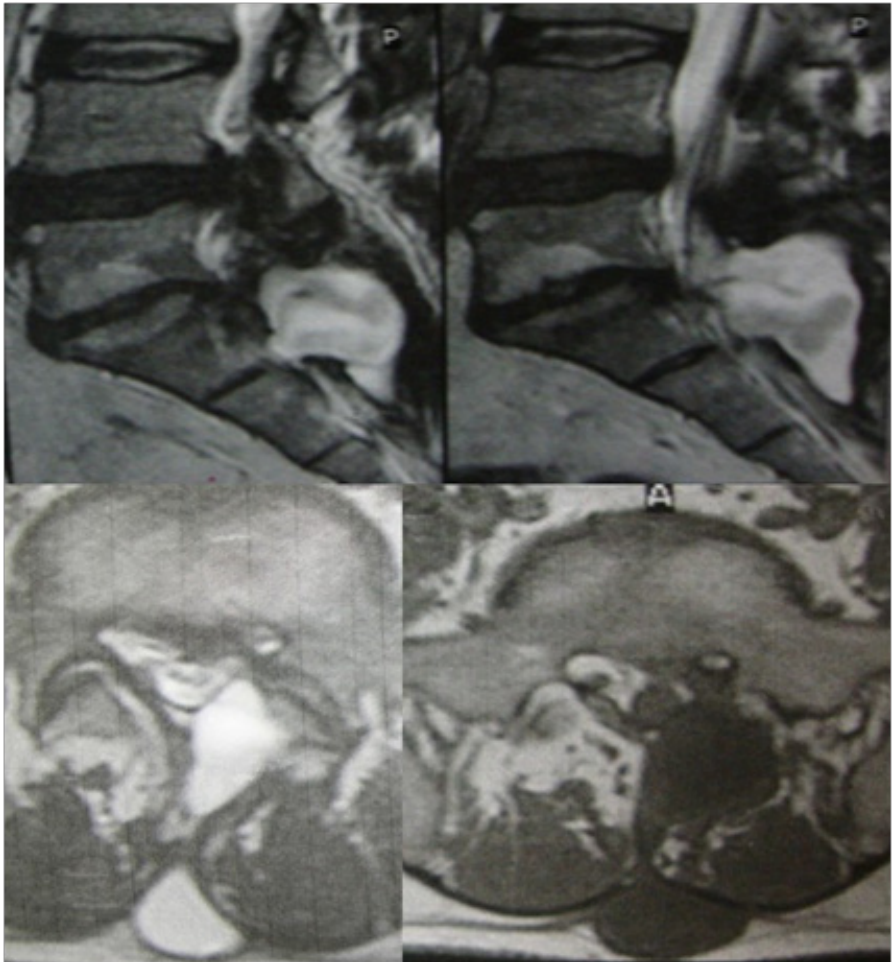

Figure 3: Pseudomeningocele - MRI, after surgery, revealed L5 laminectomy, disc protrusion paramedian on the left in L5-S1, liquid collection isointense to the CSF, without contrast impregnation, located in the laminectomy bed. Sagital and axial views.

\section{Discussion}

Iatrogenic pseudomeningoceleresults from an inadvertent surgical dural ruptura [2]. Such injury is often reported as a complication of lumbar spine surgery. This is believed to be associated with the fact that the CSF in the lumbar region has higher hydrostatic pressure than in the upright cervical spine, as well as due to the greater frequency of surgical procedures performed on the lumbar spine $[2,6]$.

The pathophysiological mechanism associated with the genesis of iatrogenic pseudomeningocele remains controversial. Some authors suggest that the arachnoid protrudes through the rupture, forming a sac, which is lined with arachnoid and filled with cerebrospinal fluid (CSF) [2][7-10]. On the other hand, other authors believe that the CSF leaks through a rupture that extends through the arachnoid and develops a fibrous capsule [6][11,12]. Therefore, it is considered that both types may exist, depending on the initial dural ruptura [2].

The communication between the pseudomeningocele and the subarachnoid space depends on the nature of the lesión [2]. When the pseudomeningocele is due to an arachnoid hernia, this communication is more likely to be maintained [2][9]. On the other hand, in cases where the injury mechanism was CSF leakage with subsequent formation of fibrous capsule, CSF leak leakage is more likely to occur [2][9].

Schumacher et al. reported that the incidences of pseudomeningoceles were less than $0.1 \%$ in a study with 3,000 patients undergoing lumbar laminectomy [3][13]. However, the incidence is much higher in complicated cases, such as spinal dysraphism or dural scarring, which occur in patients who have undergone surgery or previous radiation treatments [3][14]. Even so, the exact incidences of iatrogenic pseudomeningoceles remains unknown, which can be associated with two factors: absence of symptoms in many of the patients, or even because surgeons refuse to publish negative results [4].

The clinical presentation of the pseudomeningocele can be variable, or even asymptomatic [15]. Some cases manifest with a fluctuating mass that increases with the valsalva maneuver, similar to the clinical condition reported in this article [5]. The most common symptoms are postural headache, localized back pain and radiculopathy [4]. The entanglement of nerve roots in the pseudomeningocele and its size seem to be the main determining factors as to whether the pseudomeningocele causes symptoms or not [4].

The diagnosis of pseudomeningocele can be confirmed with clinical examination and imaging studies, especially spinal magnetic resonance imaging, and computed tomography or radionuclide myelography [2-4]. Treatment is specific to each case, varying according to size, symptoms and location [3]. Although conservative treatment, without invasive procedures, can be used in cases where the pseudocyst is small and asymptomatic; in most cases surgical repair is necessary [4].

In addition to iatrogenic pseudomeningoceles, congenital and traumatic pseudomeningoceles are also reported in the literatura [2][16-18]. Congenital pseudomeningocele is the most frequent of the three, being commonly reported in the thoracic or thoracolumbar region, and associated with neurofibromatosis or Marfan's síndrome [7][1920]. In contrast, the traumatic one is the most infrequent, being more common in the cervical región [16].

It is also worth noting that although the simple posterior bulging of the intrathecal sac due to abilateral laminectomy defect is also called post-operative pseudomeningocele, it is necessary to distinguish both clinical entities in order to avoid sources of confusión [2].

\section{Conflict of interest}

The authors declare no conflicts of interest. 


\section{References}

1. Shapiro A, Robinson F. The spine. In: Teplick JG, Haskin ME, eds. Surgical radiology. Philadelphia: Saunders, 1981: 2699- 2724

2. Teplick JG, Peyster RG, Teplick SK, Goodman LR, Haskin ME. CT Identification of postlaminectomy pseudomeningocele. AJR Am J Roentgenol. 1983;140(6):1203-6. doi: 10.2214/ajr.140.6.1203. PMID: 6602493.

3. Couture D, Branch CL Jr. Spinal pseudomeningoceles and cerebrospinal fluid fistulas. Neurosurg Focus. 2003;15(6):E6. doi: 10.3171/ foc.2003.15.6.6. PMID: 15305842 .

4. Weng YJ, Cheng CC, Li YY, Huang TJ, Hsu RW. Tratamento de pseudomeningoceles gigantes após cirurgia da coluna vertebral. BMC Musculoskelet Disord 2010; 11: 53. doi: 10.1186 / 1471-2474-1153. PMID: 20302667; PMCID: PMC2848136.

5. Rocca A, Turtas S, Pirisi A, Agnetti V. Iatrogenic lumbar pseudomeningocele. Zentralbl Neurochir. 1986;47(4):311-5. PMID: 3564761.

6. Pagni CA, Cassinani V, Bernasconi V. Meningocele spurious following hemilaminectomy in case of lumbar discal hernia. J Neurosurg 1961 18:709710.

7. Hyndman OR, Gerber WF. Spinal extradunal cysts; congenital and acquired. J Neurosurg 1946; 3:474-486.

8. Rinaldi I, Peach WF. Post-operative lumbar meningocele. J Neurosurg 1969;3O : 504-507.

9. Rinaldi I, Hodges TO. latrogenic lumbar meningocele; report of three cases. J Neurol Neurosurg Psychiatry 1970;33: 484- 492.

10. Winkler H, Powers JA. Meningocele following hemilaminectomy. N C Med J 1950;11(6):292-4.

11. Kim YW, Unger JD, Gninsell PF. Post-operative pseudo-diverticulan (spurious meningoceles) of the cervical subarachnoid space. Acta Radiol [Diagn] (Stockh) 1974;1 5:16-20.
12. Miller PR, Elder W. Meningeal pseudocysts (meningocele spunious) following laminectomy. J Bone Joint Surg [Am] 1968;50: 276-286.

13. Schumacher HW, Wassmann H, Podlinski C: Pseudomeningocele of the lumbar spine. Surg Neurol 29: 77-78, 1988

14. Zide BM, Wisoff JH, Epstein FJ: Closure of extensive and complicated laminectomy wounds. Operative technique. J Neurosurg 67:59-64, 1987

15. Rudrappa S, Govindasamy R, Tukkapuram VR, Gopal S. Lumbar pseudomeningocele presenting as decerebrate rigidity-A rare case entity. Int J Surg Case Rep. 2018;47:41-44. doi: 10.1016/j. ijscr.2018.04.014. Epub 2018 Apr 22. PMID: 29709844; PMCID: PMC5994805.

16. Barron JT. Radiologic case study. Lumbar pseudomeningocele. Orthopedics. 1990 (5):603, 608-9. PMID: 2352909.

17. Rider-Longmaid E, Huang J, Sebro R, Smith H. Intraosseous pseudomeningocele of the mobile spine: a case report and review of the literature. Eur Spine J. 2018 Jul;27(Suppl 3):472-476. doi: 10.1007/s00586-018-5498-z. Epub 2018 Jan 31. PMID: 29388089.

18. Shu W, Wang H, Zhu H, Li Y, Zhang J, Lu G, $\mathrm{Ni}$ B. Nerve root entrapment with pseudomeningocele after percutaneous endoscopic lumbar discectomy: A case report. J Spinal Cord Med. 2020 Jul;43(4):552-555. doi: 10.1080/10790268.2018.1507802. Epub 2018 Sep 13. PMID: 30211668; PMCID: PMC7480581.

19. DASTUR HM. The radiological appearances of spinal extradural arachnoid cysts. J Neurol Neurosurg Psychiatry. 1963 (3):231-5. doi: 10.1136/ jnnp.26.3.231. PMID: 14025208; PMCID: PMC1074219.

20. Maiuri F, Corriero G, Giampaglia F, Simonetti L. Lateral thoracic meningocele. Surg Neurol. 1986 (4):409-12. doi: 10.1016/0090-3019(86)90147-3. PMID: 3092383. 